\title{
Mediação da informação no campo da Arquivologia
}

\author{
Mediation of information in the field of Archival Science
}

\author{
João Arlindo dos SANTOS NETO' (iD 0000-0003-1833-911X \\ Sueli BORTOLIN1 (iD 0000-0001-7411-2716
}

\begin{abstract}
Resumo
Os estudos no âmbito da mediação da informação são frequentemente vinculados à Biblioteconomia e raramente referem-se ao campo da Arquivologia. O objetivo deste artigo é investigar como está o panorama da mediação da informação na Arquivologia, a partir da produção científica na Ciência da Informação. Como metodologia, apresenta inicialmente uma revisão de literatura sobre a temática e aplica uma pesquisa bibliográfica nos periódicos da área de Comunicação e Informação com Qualis entre A1 e B1, a partir de seus números publicados até o ano de 2017 e anais das dezoito edições do Encontro Nacional de Pesquisa em Ciência da Informação (1994-2017). Dessa forma, foram localizados 11 textos, sendo seis trabalhos do Encontro e cinco artigos de periódicos. A análise apresenta as tendências de discussão presentes nos textos recuperados, as seis categorias estabelecidas, os autores mais produtivos e mais citados, a rede de citação existente, as palavras-chave empregadas e os procedimentos metodológicos adotados. Conclui que, em sua maioria, o discurso que transparece nos textos analisados aproxima-se mais da concepção de difusão/disseminação do que da mediação. De outro lado, porém, é esta última que evidencia o arquivista como um sujeito que interfere ativamente na construção de saberes dos usuários e que reconhece seus interesses como foco do trabalho.
\end{abstract}

Palavras-chave: Arquivologia. Mediação. Mediação da informação. Mediação em arquivos.

\begin{abstract}
The studies in the ambit of mediation of information are frequently related to Library Science and rarely related to the field of Archival Science. The objective of this article is to search how the perspective of the mediation of information in Archival Science is working from the scientific production in Information Science. In the beginning, the methodology presents a literature review about the thematic and applies a bibliographic research at the journals from the Communication and Information area with Qualis between A1 and B, from its published numbers until 2017 and proceedings from the eighteen editions of Encontro Nacional de Pesquisa em Ciência da Informação (1994-2017). In this way, it was localizing 11 texts, which six are Works from the Encontro and five articles from journals. The analyses presents the tendency of discussion that are in the recovery texts, the six stablished categories, the most productive and quoted authors, the existing citation network, the used keywords and the methodological procedures used by the texts. It concludes that, for the most part, the discourse that transpires in the analyzed texts is closer to the conception of diffusion/dissemination than to mediation, since it is the one that evidences the archivist as a subject that actively interferes in the construction of users' and recognizes their interests as the focus of work.
\end{abstract}

Keywords: Archival Science. Mediation. Mediation of information. Mediation in archives.

\footnotetext{
1 Universidade Estadual de Londrina, Centro de Educação, Comunicação e Artes, Departamento de Ciência da Informação. Rod. Celso Garcia Cid, Pr 445 Km 380, Campus Universitário, 86.057-970. Londrina, PR, Brasil. Correspondência para/Correspondence to: J.A. SANTOS NETO. E-mail: <santosneto@uel.br>

Recebido em 5 de outubro de 2018, versão final reapresentada em 6 de fevereiro de 2019 e aprovada em 8 de março de 2019.
}

Como citar este artigo/How to cite this article

Santos Neto, J.A.; Bortolin, S. Mediação da informação no campo da Arquivologia. Transinformação, 31, e180067, 2019. http://dx.doi.org/10.1590/1678-98 65201931e180067 


\section{Introdução}

Estudar a produção científica de uma determinada área é imprescindível para a ciência. Esse tipo de estudo permite conhecer o panorama sobre uma temática específica bem como descobrir a elite científica responsável por sua literatura. Textos dessa natureza são subsídios aos futuros estudos que buscam conceitos e autores essenciais num determinado campo do conhecimento.

Para isso, é necessário definir o corpus documental e o período a ser analisado. Desse modo, o presente artigo buscou investigar a produção científica, na literatura nacional, em mediação da informação com aspectos direcionados à Arquivologia, mais especificamente nas publicações periódicas e nos anais de eventos que têm maior visibilidade.

Neste estudo analisaram-se as publicações periódicas com Qualis entre A1 e B1 e os anais do Encontro Nacional de Pesquisa em Ciência da Informação (Enancib), publicados até o ano de 2017, com o intuito de responder ao seguinte problema de pesquisa: como está o cenário atual da produção científica em mediação da informação sob a ótica da Arquivologia e qual é a elite responsável por ela? A problemática que resultou na questão indicada envolve diversos aspectos, dentre os quais a necessidade de se descobrir como está a discussão a respeito da mediação e quais são as perspectivas adotadas pelos autores.

A mediação é definida de diferentes formas e em diversas subáreas do conhecimento, desde Aristóteles até os dias atuais. Edgar e Sedgwick (2003, p.203) relembram que "O termo 'mediação' pode ter dois significados distintos. Em sua forma mais simples e mais próxima do senso comum, refere-se a qualquer coisa que intervenha entre outras duas coisas". E que no "[...] estudo da mídia de massa, a mediação é, portanto, qualquer coisa que (ou qualquer pessoa que) transmita uma mensagem para o público" (Edgar; Sedgwick, 2003, p.203, grifo dos autores).

A temática mediação da informação tem se mostrado mais evidente na Ciência da Informação (CI) brasileira nos últimos anos, conforme destacam Araújo (2014), Carvalho (2016), Araújo e Rocha (2017), Farias e Farias (2017) e Fialho, Nunes e Carvalho (2017). Talvez uma das motivações seja a abertura de espaços para a comunicação científica, como o GT-3 "Mediação, Circulação e Apropriação", do Enancib, e outra iniciativa em consolidação, que é o Encontro de Pesquisa em Informação e Mediação (Epim). Além disso, há os eventos que têm como foco a mediação e alguns periódicos que publicaram edições nessa temática. Existem pesquisas a respeito de mediação ligadas à Biblioteconomia, poucos trabalhos de pesquisa na Arquivologia (Lousada; Almeida Júnior, 2013; Santos Neto; Bortolin, 2017) e alguns na Museologia, voltados para mediação cultural.

Assim, essas áreas e a Cl não podem se eximir dessa função, assim como bibliotecários, arquivistas, museólogos e outros profissionais. No entanto, o foco deste estudo é a Arquivologia, que teve uma trajetória semelhante à da Biblioteconomia, pois também iniciou com um forte traço tecnicista e, muitas vezes, hermético. Isso acabou levando os profissionais da área a se apoiarem com rigor em padrões que muitas vezes distanciam os usuários dos arquivos. Assim como nas bibliotecas, durante muito tempo, imperava nos arquivos o pensamento e o comportamento de preservar, e não de mediar ou permitir aos indivíduos a liberdade de uso, sem a criação de barreiras às diferentes fontes.

É compreensível que, diante do caráter único de um documento histórico, por exemplo, o livre acesso ao acervo tenda a causar-Ihe danos; porém, ao considerar a mediação da informação no arquivo, o profissional não pode esquecer que o uso de tecnologias, como a microfilmagem de originais, permite e facilita as pesquisas.

A mediação da informação no âmbito da Cl, definida em 2008 e reformulada em 2015 por Almeida Júnior, está presente e tem se solidificado nos discursos e publicações da área, configurando-se como uma necessidade premente. Para ele, mediação da informação é:

[...] toda ação de interferência - realizada em um processo, por um profissional da informação e na ambiência de equipamentos informacionais -, direta ou indireta; consciente ou inconsciente; 
singular ou plural, individual ou coletiva; visando a apropriação de informação que satisfaça, parcialmente e de maneira momentânea, uma necessidade informacional, gerando conflitos e novas necessidades informacionais (Almeida Júnior, 2015a, p.25).

A presente definição foi discutida por Santos Neto e Bortolin (2017), quando destacaram quatro elementos: interferência, processo, apropriação e conflito.

Compreende-se a interferência como a ação cotidiana do arquivista quando este colabora com os usuários em suas buscas por informação de maneira presencial ou virtualmente. Podem-se citar, dentre outras, algumas situações cotidianas em que a interferência do arquivista é evidente: (a) descarte inadequado de documentos sem acatar diretrizes constantes na tabela de temporalidade; (b) não elaboração ou cumprimento de políticas que norteiam a constituição de acervos; (c) desatenção quanto a editais e agências de fomento que permitam o acondicionamento, a conservação e a preservação adequada dos acervos; (d) estabelecimento do setor de referência para atendimento ao público; (e) despreparo ou disposição para prestar serviços/produtos com a destreza exigida nos dias atuais.

Quanto ao processo, Almeida Júnior (2009) classifica a mediação em implícita ou explícita. A primeira se dá em um processo contínuo e visa a organizar a informação existente em diferentes ambientes e suportes, com a intenção de suprir necessidades e suscitar nos usuários, em um movimento pendular, outras e novas necessidades. Já a mediação explícita, dependendo do gênero de dispositivo, ocorre de maneira presencial ou à distância. Relaciona-se a esses processos a dialogia apresentada por Gomes (2014), quando diferentes sujeitos estão envoltos na mediação, compartilhando informação e gerando significados. Assim como para o bibliotecário, a entrevista de referência possibilita ao arquivista compreender o que o usuário quer e/ou precisa, além de aproximá-lo do arquivo. Outros processos a serem considerados são: diagnóstico, produção documental, classificação, descrição, avaliação, tramitação dos documentos e transferência dos mesmos (Santos Neto; Bortolin, 2017).

Quanto à apropriação, ela ocorre no momento em que o usuário atribui significado(s) à informação, sendo, portanto, um ato pessoal e singular do indivíduo, que ocorre num contexto que é social. Vale destacar que a apropriação da informação se renova à medida que o conhecimento do indivíduo se amplia e suas leituras de mundo se diversificam. Assim, por exemplo, uma iniciativa que pode aproximar os cidadãos de um arquivo municipal, para que eles se apropriem de dados históricos de sua cidade, seria a exposição dos documentos que justificam a escolha dos nomes de ruas, praças, escolas e demais patrimônios públicos.

Por fim, o conflito, é dependente de aspectos psicológicos, cognitivos, culturais e ideológicos, que farão (ou não) com que a informação tenha sentido, responda a questionamentos e provoque o surgimento de outros.

É salutar lembrar que a defesa da presença cotidiana de atos mediativos na Cl tornou-se óbvia em consequência da percepção de que, sem o sujeito (cidadão, leitor, usuário ou outra denominação, como consulente, cliente ou utente), o acervo, apesar de sua importância histórica e social, na prática não alcança a sua função legítima. Para Duff (2016, p.171), "[...] a promessa de acesso universal ao material arquivístico não se concretizará a não ser que haja arquivistas disponíveis para ajudar na mediação entre os usuários e o que eles buscam".

Referindo-se também aos arquivistas, Morigi e Veiga (2007, p.32) defendem que eles "[...] podem ser agentes mediadores, capazes de implementar critérios que venham a disponibilizar os registros informacionais, possibilitando o acesso destes aos cidadãos". Desse modo, observa-se a necessidade de que os arquivistas se reconheçam como mediadores, pois, além de lidar com tabelas e instrumentos de trabalho (que não são neutros), a interferência deflagrada em distintos momentos de seu fazer não pode ser negada no dia a dia. Vale destacar ainda que focar apenas as bibliotecas, os arquivos e os museus, sem avaliar os atos dos profissionais que atuam nesses lugares, faz com que se perceba a mediação como uma ação amorfa, morna e apagada. Na atualidade, requerem-se dos mediadores "fortes" intenções de mudar realidades, isto é, que sejam protagonistas capazes de enriquecer os que estão sob a égide das referidas unidades de informação. 
Mesmo que o número de pesquisas a respeito de mediação nos arquivos seja ínfimo em terras brasileiras, é ético afirmar que talvez os arquivistas estejam realizando ações nesse sentido, mas não as fazem com regularidade e/ou não as socializam em canais de comunicação de pesquisa científica. Outra possibilidade é a visão elitista e equivocada que paira em torno do arquivo, visto que "[...] os arquivos estão premidos entre dois extremos: de um lado, a cultura para o usuário erudito e o cientista; de outro, a cultura para todos" (Bellotto, 2006, p.241), pois, ao se priorizar apenas um grupo de usuários, elitiza-se o acesso ao arquivo.

Constatam-se, por outro lado, experiências em arquivos utilizando o termo difusão, ao invés de mediação. Bellotto, em sua obra Arquivos permanentes: tratamento documental, no capítulo denominado "Difusão editorial, cultural eeducativa emarquivos", cita, desde 2006, diferentes serviços educativos nos arquivos franceses, evidenciando o seu caráter didático. Por outro lado, o uso da palavra difusão, muito comum no campo da Arquivologia, é discutido por Rockembach (2015, p.100) quando adverte que: "O Dicionário Brasileiro de Terminologia Arquivística (2005) não traz o termo 'difusão', mas se aproxima quando conceitua Disseminação da Informação [...]".

No entanto, concorda-se com Almeida Júnior (2015b) quando defende que a ideia de mediação é mais abrangente que a de disseminação, uma vez que esta, ao invés de se preocupar com a apropriação da informação, foca no acesso físico do documento pelo usuário e, portanto, estaria mais vinculada à transferência da informação que com a mediação da informação.

A palavra disseminação demonstra uma postura passiva (o mediador faz para), enquanto a mediação é mais ativa (o mediador faz com). Dessa forma, todo ato mediativo, além de tornar o arquivo e o arquivista presentes na vida do cidadão, concretiza a dimensão ética proposta por Gomes (2014) quanto à mediação da informação. É possível relacionar a dimensão ética da mediação com o impacto da difusão em arquivos, que, segundo Bellotto (2006, p.227), é a atividade que "[...] melhor pode desenhar os seus contornos sociais, dando-lhe projeções na comunidade, trazendo-Ihe a necessária dimensão popular e cultural que reforça e mantém o seu objetivo [...]" de servir ao administrador, cidadão e historiador. Isso demonstra o caráter ético dos serviços arquivísticos.

Acredita-se, ao encerrar esta revisão, que é imprescindível evidenciar o pensamento de Finazzi-Agrò (2003, p.63) quando afirma que o mediador é "[...] destinado a não ter nunca um lugar próprio ou fixo, a não ter uma pátria, mas a se colocar, isso sim, entre as pátrias, na fronteira onde sentidos diferentes se enfrentam e/ou se misturam". Nesse discurso, destaca-se o esforço do mediador em, na medida do possível, ser transigente, despindo-se de preconceitos e trabalhando para valorizar as diversidades, sejam elas de natureza cultural, social, religiosa, filosófica, política ou de gênero. Assim, ser mediador é tomar para si o compromisso de participar, de forma ética, da vida escolar, acadêmica, política e social, para que possa modificar a maneira de ser e estar no mundo.

\section{Procedimentos Metodológicos}

O artigo possui caráter exploratório e descritivo, visto que busca o aprofundamento nas discussões que envolvem a mediação no campo da Arquivologia. O intuito desse levantamento foi identificar e analisar, nessas publicações, a forma como a mediação é reconhecida pelos pesquisadores que publicaram textos envolvendo o campo da Arquivologia. Para tal, utilizou-se dos métodos bibliométricos e cientométricos.

De acordo com Santos e Kobashi (2009), a bibliometria analisa a quantidade de produções em um determinado contexto, enquanto a cientometria investiga outros elementos, como as atividades de citações, por exemplo. Para Silva, Hayashi e Hayashi (2011), ambos são métodos de pesquisa que deveriam ser empregados conjuntamente, visto que ao mesmo tempo que se preocupam com aspectos distintos, eles se complementam.

As buscas foram realizadas em todas as edições do Enancib e nos números de periódicos disponíveis eletronicamente até 2017. Quanto aos periódicos, selecionaram-se aqueles nacionais e internacionais com estrato Qualis A1, A2 e B1 na área de avaliação Comunicação e Informação, no quadriênio 2013-2016. 
A seleção dos textos que constituíram o corpus da análise se deu a partir da ocorrência, nos títulos, do termo mediação, obrigatoriamente, relacionado a Arquivologia, Arquivos, Arquivística etc. Os textos foram lidos e analisados e, em seguida, comparados às discussões existentes, procurando compreender como o discurso a respeito da mediação tem sido explicitado pelos pesquisadores, bem como apresentar as percepções desses autores sobre a temática.

Como técnica de análise, foi empregada a Análise de Conteúdo (AC), que, segundo Bardin (2005), refere-se a um conjunto de procedimentos "[...] sistemáticos e objetivos de descrição de conteúdo das mensagens, indicadores (quantitativos ou não) que permitam a inferência de conhecimentos relativos às condições de produção/recepção (variáveis inferidas) destas mensagens".

Neste artigo utilizou-se especificamente a abordagem categorial da AC, que, segundo as proposições de Bardin (2005, p.36), nesse tipo de análise "[...] pretende tomar em consideração a totalidade de um <texto>, passando-o pelo crivo da classificação e do recenseamento, segundo a frequência de presença (ou de ausência) de itens de sentido".

Durante a análise foi possível vislumbrar quem são os pesquisadores responsáveis por apresentar as discussões que inserem a mediação na Arquivologia, bem como os autores citados por eles. Atentou-se também para o emprego das palavras-chave que foram utilizadas e, na sequência, adotou-se a Lei do Elitismo (Price, 1963). "Segundo esta lei, se k representa o número total de contribuintes numa disciplina, $\sqrt{ }$ k representaria a elite da área estudada, assim como o número de contribuintes que gera a metade de todas as contribuições" (Urbizagástegui Alvarado, 2009, p.70). Após a identificação das elites, foram elaboradas no processador de dados Excel as matrizes entre citante e citado dos artigos de periódicos e trabalhos do Enancib, para construção da rede de citação, utilizando o software Ucinet 6 for Windows, versão 6.652 (Analytic Technologies, Lexington, Kentucky, Estados Unidos).

Procurou-se neste artigo não somente mapear a produção científica acerca da mediação no âmbito da Arquivologia, mas também analisar e discutir as concepções adotadas nos textos e a forma como a mediação tem sido discutida. Os dados são apresentados na seção a seguir, com o uso de figuras e quadros.

\section{Resultados e Discussão}

No total, foram recuperados 11 textos: seis trabalhos dos anais do Enancib e cinco artigos de periódicos, conforme ilustra o Quadro 1. Os textos recuperados são apresentados por ano de publicação, em ordem decrescente.

Os autores mais produtivos são Aldabalde, T.V.; Almeida Júnior, O.F. e Lousada, M., com três publicações cada um, considerando-se as coautorias. Um pesquisador possui dois textos publicados na temática, e os demais apenas um. Reconhece-se, portanto, que os três autores supracitados são responsáveis pela produção de sete dos 11 textos analisados. Sendo assim, a Lei do Elitismo pôde ser comprovada nesta investigação, pois a elite dos autores é responsável por mais de 50\% dos textos publicados. Ainda em relação à autoria dos textos, dois dos três autores mais produtivos (Almeida Júnior e Lousada) são orientador e ex-orientanda respectivamente, ou seja, o contexto também interferiu no número de produções.

Ao consultar a quantidade de citados nos textos, chegou-se a um total de 155 autores. Para esta análise, foram computados todos os autores citados nos casos de produção em coautoria - desconsiderando-se as coautorias e autorias institucionais. De acordo com a Lei de Price ou Lei do Elitismo (Price, 1963; Urbizagástegui Alvarado, 2009), a raiz quadrada do número total de um recorte representa a elite acadêmica do universo estudado. Mesmo esta Lei sendo direcionada para estudos de produtividade, optou-se pelo método da raiz quadrada também para obter um índice aproximado e representativo dos autores mais citados, resultando em 14 pesquisadores que foram mencionados no mínimo seis vezes. Apresentam-se no Quadro 1 os nomes dos citados, em ordem decrescente conforme o número de citações. 
Quadro 1. Textos recuperados para análise.

\begin{tabular}{|c|c|c|c|}
\hline N & Título & Autor(es) & Fonte \\
\hline 1 & $\begin{array}{l}\text { Mediação cultural em arquivos públicos: análise das práticas } \\
\text { e tipologias no Arquivo Público do Estado do Espírito Santo }\end{array}$ & $\begin{array}{l}\text { Aldabalde, T.V. \& Rodrigues, G.M. } \\
\text { (2016) }\end{array}$ & XVII Enancib \\
\hline 2 & $\begin{array}{l}\text { Arquivologia e mediação: agenciamentos e visibilidades pelo } \\
\text { saber/poder/fazer }\end{array}$ & $\begin{array}{l}\text { Grigoleto, M.C. \& Aldabalde, T.V. } \\
\text { (2016) }\end{array}$ & XVII Enancib \\
\hline 3 & $\begin{array}{l}\text { A mediação da informação e a Arquivologia: aproximações } \\
\text { teóricas }\end{array}$ & Lousada, M. (2016) & $\begin{array}{l}\text { Pesquisa Brasileira em Ciência da } \\
\text { Informação e Biblioteconomia }\end{array}$ \\
\hline 4 & A mediação da informação na teoria arquivística & $\begin{array}{l}\text { Lousada, M. \& Almeida Júnior, O.F. } \\
\text { (2016) }\end{array}$ & XVII Enancib \\
\hline 5 & $\begin{array}{l}\text { Mediação da informação em arquivos: a necessidade de } \\
\text { consolidação da prática do serviço de referência }\end{array}$ & $\begin{array}{l}\text { Santa Anna, J. \& Campos, S.O. } \\
\text { (2016) }\end{array}$ & Biblionline \\
\hline 6 & $\begin{array}{l}\text { Mediação cultural no Arquivo Público do Estado do Espírito } \\
\text { Santo }\end{array}$ & $\begin{array}{l}\text { Aldabalde, T.V. \& Rodrigues, G.M. } \\
\text { (2015) }\end{array}$ & TransInformação \\
\hline 7 & A mediação da informação no âmbito da arquivística & $\begin{array}{l}\text { Ferreira, L.E. \& Almeida Júnior, O.F. } \\
\text { (2013) }\end{array}$ & $\begin{array}{l}\text { Perspectivas em Ciência da Infor- } \\
\text { mação }\end{array}$ \\
\hline 8 & $\begin{array}{l}\text { A mediação da informação na teoria arquivística: aspectos } \\
\text { epistemológicos }\end{array}$ & $\begin{array}{l}\text { Lousada, M. \& Almeida Júnior, O.F. } \\
\text { (2013) }\end{array}$ & XIV Enancib \\
\hline 9 & $\begin{array}{l}\text { Mediação como conceito potencializador do diálogo entre } \\
\text { a Ciência da Informação e os campos da Arquivologia, } \\
\text { Biblioteconomia e Museologia }\end{array}$ & Araújo, C.A.Á. (2012) & XIII Enancib \\
\hline 10 & $\begin{array}{l}\text { A mediação da informação nos arquivos permanentes: } \\
\text { serviços de referência arquivística no ambiente digital }\end{array}$ & Gama, F.A. \& Ferneda, E. (2010) & Informação \& Informação \\
\hline 11 & $\begin{array}{l}\text { Relações pendulares na mediação da informação: arquivo- } \\
\text {-biblioteca-museu }\end{array}$ & $\begin{array}{l}\text { Espírito Santo, S.M. \& Murguia, E. } \\
\text { (2006) }\end{array}$ & VII Enancib \\
\hline
\end{tabular}

Fonte: Elaborado pelos autores (2018).

De acordo com o ranking apresentado no Quadro 2, Almeida Júnior, O.F. aparece como o mais citado, com 26 citações. Em seguida, Smit, J.W. obteve 16; Cook, T., 15; Silva, A.M., 11; Bellotto, H.L. e Buckland, M.K., 10 citações cada um; e Almeida, M.A., nove. Os demais autores receberam seis citações cada um. Vale ressaltar que, ao computar as autocitações, chegou-se a um total de 11 ocorrências, isto é, menos de 10\% de todas as citações analisadas. Vale observar ainda que os autores mais citados são os referentes mais importantes, mas não necessariamente aderentes à questão de pesquisa que o trabalho enfoca: mediação da informação no campo da Arquivologia.

A partir das respectivas trajetórias e produções científicas dos 13 pesquisadores, foi possível classificá-los em três domínios: alguns investigam especificamente a mediação, outros voltam seus estudos para a Arquivologia e outros mais se dedicam à $\mathrm{Cl}$ como um todo. Ao buscar a origem acadêmica dos autores, constatou-se que a maioria não tem formação em Arquivologia, exceto quatro (Aldabalde, T.V.; Lousada, M.; Campos, S.O.; Ferreira, L.E.). Os demais são oriundos de Biblioteconomia (Almeida Júnior, O.F.; Santa Anna, J.), História (Rodrigues, G.M.; Grigoleto, M.C.; Murguia, E.), Administração de Empresas (Gama, F.A.), Sociologia (Espírito Santo, S.M.), Jornalismo (Araújo, C.A.A.) e Processamento de Dados (Ferneda, E.).

Com o intuito de conhecer a rede de citação existente entre os autores/citados dos textos analisados, a Figura 1 apresenta o panorama encontrado.

A partir da rede (Figura 1), constata-se inicialmente sua constituição por um número reduzido de autores, o que a torna relativamente pequena. Além disso, há um baixo número de nós, bem como a ocorrência de autores 
Quadro 2. Ranking dos autores mais citados pelos textos.

\begin{tabular}{lc}
\hline Autores & No de Citações \\
\hline Almeida Júnior, O.F. & 26 \\
Smit, J.W. & 16 \\
Cook, T. & 15 \\
Silva, A.M. & 11 \\
Bellotto, H.L. & 10 \\
Buckland, M.K. & 10 \\
Almeida, M.A. & 9 \\
Bizello, M.L. & 6 \\
Foucault, M. & 6 \\
Gomes, H.F. & 6 \\
Graciano, M.E.T. & 6 \\
Pieruccini, I. & 6 \\
Ribeiro, F. & 6 \\
Silva, J.L.C. & 6 \\
\hline
\end{tabular}

Fonte: Elaborado pelos autores (2018).

Rodrigues, G.M

Araújo, C.A.Á.

Espírito Santo, S.M

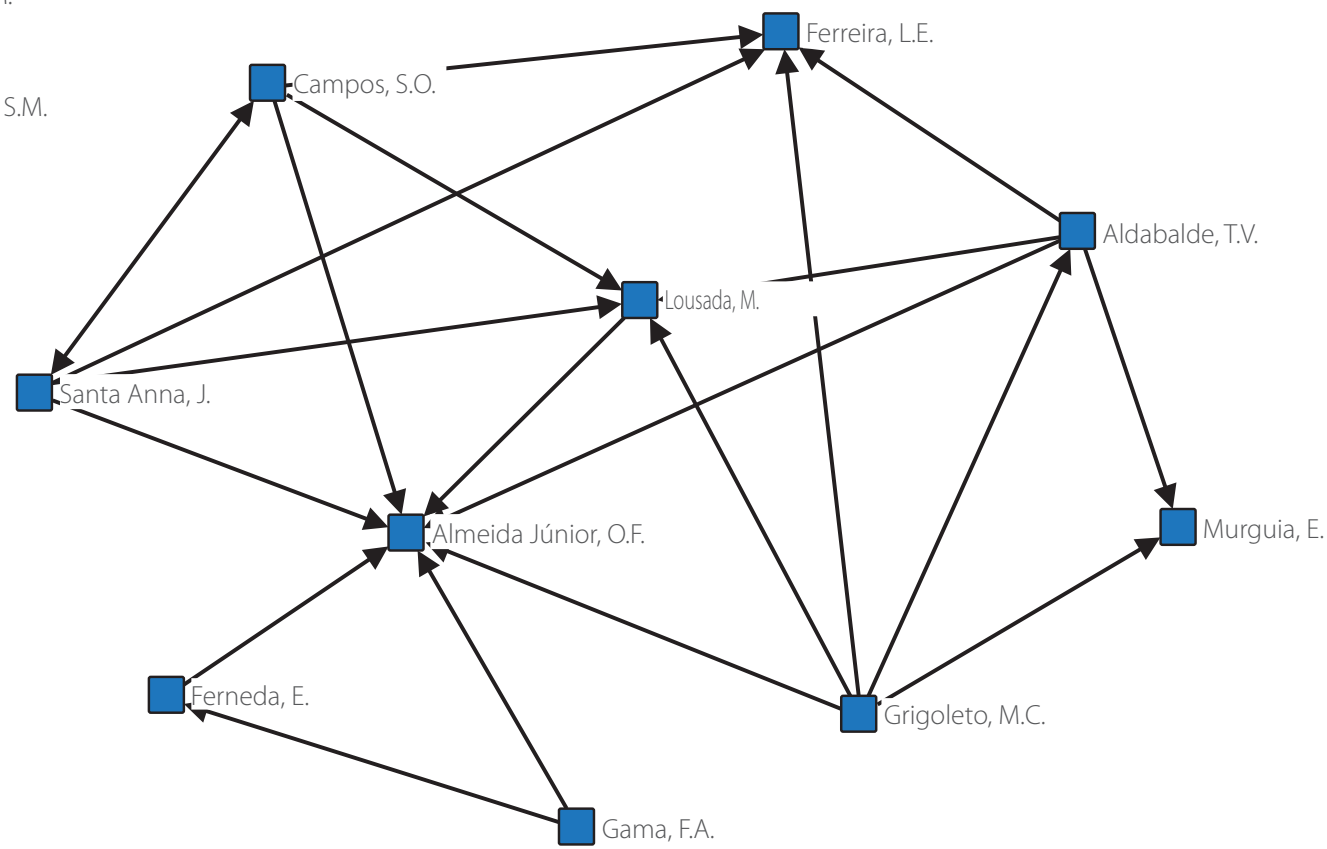

Figura 1. Rede de citação autor/citado.

Fonte: Elaborado pelos autores (2018).

isolados, que não obtiveram citação (Rodrigues, G.M.; Araújo, C.A.A.; Espírito Santo, S.M.) e por esse motivo não compuseram a rede. Por outro lado, observa-se que entre os autores mais citados não há uma reciprocidade em relação ao ato de citar. Destaca-se que, na rede, Almeida Júnior, O.F.; Ferreira, L.E. e Lousada, M. aparecem como os mais citados, sendo que dois deles também são os mais produtivos, o primeiro e o último, respectivamente. Além disso, vale mencionar que o primeiro autor é coautor juntamente com os outros dois. 
Dos 11 textos, 10 apresentaram 42 palavras-chave e um deles não apresentou nenhuma. Após o agrupamento dos termos empregados mais de uma vez, foram identificados 29. As palavras-chave mais utilizadas pelos autores foram: Mediação da informação (7), presente em 63\% dos artigos, seguida pelos termos Arquivologia (4), Mediação cultural (3), Abordagem canadense (2) e Arquivística pós-moderna (2). Os demais termos (24) foram empregados somente uma vez, quais sejam: Arquitetura da informação; Arquivística; Arquivo; Arquivo Público do Estado do Espírito Santo; Arquivos permanentes; Arquivos públicos; Ciência da Informação; Comportamento informacional; Cultura; Descrição arquivística; Difusão; Epistemologia; Espectro; Instituições; Linguagens de marcação; Organização arquivística; Organização do conhecimento; Papéis profissionais; Pêndulo; Saber/poder/fazer; Serviço de referência; Serviço de referência em unidades de informação; Serviços de extensão cultural; e Tipologias de práticas culturais.

Dessa análise, infere-se que muitos termos são genéricos e pouco representam o conteúdo dos textos, o que pode resultar na não recuperação deles. Entre esses termos, destacam-se: Arquivo, Arquivologia, Ciência da Informação, Cultura, Instituições e Pêndulo.

Por fim, discutiram-se os procedimentos adotados nos textos analisados. Primeiramente, buscaram-se tais informações no resumo dos textos e, quando não localizadas, recorreu-se à seção de metodologia.

Os métodos mais utilizados pelos pesquisadores foram a pesquisa bibliográfica/revisão de literatura. No entanto, os autores não deixam evidente a diferença entre um e outro, uma vez que o primeiro envolve critérios prévios e delimitações (temporais, geográficas, de idiomas etc.), e o segundo é obrigatório para qualquer produção científica. Em seguida, os outros métodos adotados foram a pesquisa histórico-documental e a pesquisa aplicada, ressalvando-se que se acredita que esta última se refere à natureza da pesquisa e não ao método propriamente dito. Em alguns casos constatou-se o uso de mais de um método e, dos 11 textos analisados, seis não explicitaram claramente o percurso metodológico adotado, o que requereu análise e inferência dos proponentes desta pesquisa.

Quanto às técnicas e instrumentos de coleta, a entrevista e os formulários foram os mais utilizados. Vale ressaltar ainda que somente um texto indicou a análise estatística como técnica de análise dos dados e, entre os demais, não foi possível identificar a(s) técnica(s) de análise utilizada(s), inferindo-se que na maioria dos casos empregou-se a análise categorial, que é oriunda da Análise de Conteúdo (AC).

Ao analisar o conteúdo dos textos com o intuito de se compreender a forma como a mediação da informação é discutida no campo da Arquivologia, estabeleceram-se, a partir da AC, as seguintes categorias: (a) Significado da mediação; (b) Características da mediação; (c) Tipos de mediação; (d) Ocorrência da mediação; (e) Efetivação da mediação; (f) Repercussões da mediação. Essas categorias foram estabelecidas a partir da proximidade dos discursos explicitados nos textos e conduziram a análise que é exposta a seguir.

a) Significado da mediação: refere-se à ação de interferência realizada pelo profissional da informação, em que não há espaço para neutralidade (Gama; Ferneda, 2010; Araújo, 2012; Ferreira; Almeida Júnior, 2013; Lousada, 2016; Lousada; Almeida Júnior, 2016; Santa Anna; Campos, 2016). Essa concepção é formulada a partir da conceituação proposta por Almeida Júnior (2009) e reformulada em 2015. Esses autores seguem a linha de pensamento de Almeida Júnior, que propõe a ideia de mediação como algo desprovido de imparcialidade, visto que os profissionais lidam com decisões (direcionadas ou não por distintas instituições) e, logo, interferem nos processos e práticas informacionais.

Outra concepção encontrada em dois textos foi reconhecer a mediação como objeto de estudo da Biblioteconomia e Cl, conforme apresentaram Ferreira e Almeida Júnior (2013) e Grigoleto e Aldabalde (2016). A proposição da mediação como objeto, no lugar da informação, advém da defesa de que a própria área abarca elementos efêmeros que, depois de registrados, não são aptos a reproduzir fielmente todas as possibilidades de sentidos, interpretações e recepções ao sujeito que lidará com eles, conforme também foi apontado por Almeida Júnior (2009). 
Outra interpretação advém de Araújo (2012) e de Grigoleto e Aldabalde (2016), quando consideram a mediação como abordagem contemporânea e como subárea que ocupa devidamente seu lugar na Cl. Numa linha de pensamento que se aproxima desta, Araújo (2012) defende a potencialidade da mediação como conceito para integrar a Arquivologia, a Biblioteconomia e a Museologia.

Espírito Santo e Murguia (2006), por sua vez, atribuem à mediação o sentido de apropriação, interface, decorrente do encontro entre sujeito e informação, que se dá em um processo.

b) Características da mediação: dos textos aqui analisados, somente dois atribuíram características para a mediação. Primeiro, Espírito Santo e Murguia (2006) consideram-na como uma decorrência estética e sensorial; em complemento, Santa Anna e Campos (2016) vislumbram que a mediação é dialógica, receptiva e acolhedora. Ambos os discursos podem ser relacionados ao que Gomes (2014) elucidou, ao discutir os aspectos dialógicos, estéticos, formativos e éticos da mediação.

c) Tipos de mediação: quanto à categorização da mediação, a que obteve mais ocorrência foi a proposta por Almeida Júnior (2009), que é dividida em mediação explícita e implícita. Essa classificação foi apontada por Ferreira e Almeida Júnior (2013), Lousada (2016), Lousada e Almeida Júnior (2016), Santa Anna e Campos (2016).

Vale lembrar que a mediação explícita se configura como as ações que ocorrem com a participação do usuário, mediante sua presença física ou mesmo remota. A mediação implícita, por sua vez, refere-se às ações em que a presença do usuário é dispensável. Assim sendo, Gama e Ferneda (2010) e Santa Anna e Campos (2016) relacionaram a mediação explícita da informação ao Serviço de Referência que é oferecido nos arquivos. Por outro lado, ainda que os autores dos textos não tenham especificado possibilidades de mediação implícita, indicam-se aquelas apontadas e discutidas por Santos Neto e Bortolin (2017), que são voltadas ao tratamento e descrição documental, entre elas o diagnóstico, a produção documental, a classificação, a avaliação, a tramitação, a transferência, o recolhimento e a conservação dos documentos.

Outras duas formas de mediação foram apontadas por Lousada (2016) e por Lousada e Almeida Júnior (2016): mediação custodial e mediação pós-custodial. Essa concepção pode ser relacionada ao discurso de Malheiro e Ribeiro (2011), quando diferenciam o paradigma custodial (quando a guarda e preservação das coleções do patrimônio são prioridade nas instituições) e o paradigma pós-custodial (quando o acesso e a disponibilização, física ou eletrônica, passam também a ser prioridade das instituições).

Por fim, Aldabalde e Rodrigues $(2015,2016)$ discutem uma modalidade específica de mediação nos arquivos: a mediação cultural. Esta ocorre a partir das práticas culturais deflagradas no arquivo e historicamente são aquelas mais trabalhadas nessas instituições. Esses autores se baseiam principalmente no discurso de Teixeira Coelho (1997, p.248), que considera a mediação cultural como "processos de diferente natureza cuja meta é promover a aproximação entre indivíduos ou coletividades e obras de cultura e arte".

Com o intuito de exemplificar ainda mais as possibilidades de ações culturais realizadas nos arquivos, recorre-se ao discurso de Bellotto (2006, p.228), quando afirma que as iniciativas promovidas por alguns arquivos brasileiros são principalmente "[...] palestras, debates, lançamentos de obras e concursos sobre temas de história geral do Brasil e história regional [...] simpósios, congressos, jornadas e reuniões, não só sobre a profissão e a prática arquivística e/ou histórica [...]", mas também de outras áreas do conhecimento.

d) Ocorrência da mediação: Lousada e Almeida Júnior (2013, 2016), Grigoleto e Aldabalde (2016), Lousada (2016) e Santa Anna e Campos (2016) reconhecem que a mediação perpassa todos os processos e práticas arquivísticas, isto é, desde a produção à destinação final dos documentos. Assim sendo, o arquivista interfere em distintos momentos no seu fazer profissional, conforme argumenta Almeida Júnior (2009).

Ao indicar uma mediação, Gama e Ferneda (2010) e Lousada e Almeida Júnior (2016) apontam o mesmo exemplo: a elaboração dos instrumentos arquivísticos. Esse fazer, por sua vez, vai ao encontro da conceituação de mediação implícita da informação, conforme sugerido por Almeida Júnior (2009). 
e) Efetivação da mediação: para Ferreira e Almeida Júnior (2013), a mediação se efetiva quando os arquivos cumprem sua função social e garantem o direito aos cidadãos. Esse pensamento também é apresentado por Bellotto (2006), ao afirmar que a cultura é um direito de todos, sendo dever do arquivo, especificamente se público, servir à comunidade, ao historiador etc.

f) Repercussões da mediação: Espírito Santo e Murguia (2006), Ferreira e Almeida Júnior (2013) e Santa Anna e Campos (2016) entendem que, após deflagrado o ato da mediação, ocorre um processo de transformação e construção de conhecimento nos mediandos e, acrescentam-se aqui, também nos mediadores, que podem aprender juntos durante o processo. Almeida Júnior (2015a) reforça esse pensamento quando afirma que a mediação, além de satisfazer parcial e momentaneamente uma necessidade informacional, também desperta novas necessidades e conflitos informacionais.

Nesse ponto, acredita-se ser necessário destacar que as categorias estabelecidas - significado da mediação, características da mediação, tipos de mediação, ocorrência da mediação, efetivação da mediação e repercussões da mediação -, foram decisivas para o alcance dos objetivos deste artigo, possibilitando investigar o panorama da mediação da informação na perspectiva da Arquivologia, a partir da produção científica.

\section{Considerações Finais}

Os autores deste artigo realizam investigações diuturnamente a respeito de mediação da informação, mas em geral na Biblioteconomia. Neste estudo, o desafio foi investigar a mediação na Arquivologia e para isso utilizaram-se os princípios bibliométricos (técnica em expansão na Cl brasileira). Após sua realização, foi possível confirmar que, além de escasso o número de pesquisas voltadas à Arquivologia e Mediação, o conceito de mediação ainda é discutido de maneira tímida pelos pesquisadores da temática arquivística, o que indica a necessidade de maior atenção e dedicação ao tema. É necessário também evidenciar que os profissionais dos arquivos, ao utilizar o termo difusão, talvez não tenham constatado que a dimensão proposta pela teoria da mediação possa ampliar a valoração e enaltecer as suas práticas.

Mesmo que incipiente, devido à novidade em torno das discussões sobre mediação da informação no campo da Arquivologia, este artigo apresenta e discute os textos que foram publicados até o ano de 2017 nos periódicos e anais do Enancib. Ainda que o corpus de análise selecionado seja expressivo, após delimitação foram recuperadas somente 11 produções. No entanto, esse panorama não inviabilizou os estudos de natureza bibliométrica e cientométrica. Acredita-se que as inferências e análises realizadas justificam a realização do estudo em um corpus seleto como este apresentado.

As argumentações existentes tanto nos artigos quanto na literatura pertinente evidenciaram a possibilidade de interferência do arquivista em momentos distintos no seu cotidiano profissional. Consequentemente, os discursos avivaram a sua imprescindível presença nos arquivos. Para tanto, exige-se dos mediadores tanto conhecimento técnico quanto outras habilidades, como dinamismo, criatividade, atualização e perseverança. Em outras palavras, que o arquivista venha acompanhado de um latente desejo de que o interesse dos usuários seja a meta a ser alcançada.

Dessa forma, além de aproximar o usuário do documento, visando o seu enriquecimento cognitivo e cultural, é necessário que a Arquivologia amplie sua pauta de pesquisa com a temática Mediação.

\section{Colaboradores}

J.A. Santos Neto colaborou com a concepção, normalização, desenho, coleta, análise e interpretação dos dados, elaboração das considerações finais e revisão. S. Bortolin colaborou com concepção, análise e interpretação dos dados, elaboração das considerações finais, revisão e aprovação da versão final. 


\section{Referências}

Aldabalde, T.V.; Rodrigues, G.M. Mediação cultural em arquivos públicos: análise das práticas e tipologias no Arquivo Público do Estado do Espírito Santo. In: Encontro Nacional de Pesquisa em Ciência da Informação, 17., 2016, Salvador. Anais eletrônicos [...]. Salvador: UFBA, 2016. Disponível em: http://repositorios.questoesemrede.uff.br/repositorios/ handle/123456789/3239. Acesso em: 14 set. 2018.

Aldabalde, T.V.; Rodrigues, G.M. Mediação cultural no Arquivo Público do Estado do Espírito Santo. Transinformação, v.27, n.3, p.255-264, 2015. Doi: http://dx.doi.org/10.1590/010337862015000300007. Disponível em: http://www.scielo.br/ scielo.php?pid=S0103-37862015000300255\&script=sci_ abstract \&tlng=pt. Acesso em: 20 set. 2018.

Almeida Júnior, O.F. Mediação da informação e múltiplas linguagens. Tendências da Pesquisa Brasileira em Ciência da Informação, v.2, n.1, p.89-103, 2009. Disponível em: http://ojs. lat/tpbci/index.php/tpbci/article/view/37. Acesso em: 3 set. 2018.

Almeida Júnior, O.F. Mediação da informação: um conceito atualizado. In: Bortolin, S.; Santos Neto, J.A.; Silva, R.J. (Org.) Mediação oral da informação e da leitura. Londrina: Abecin, 2015a. p.9-32.

Almeida Júnior, O.F. Mediação da informação: dimensões. 2015b. Disponível em: https://ofaj.com.br/colunas_conteudo. php?cod=939. Acesso em: 10 set. 2018.

Araújo, C.A.Á. Arquivologia, Biblioteconomia, Museologia e Ciência da Informação: o diálogo possível. Brasília: Briquet de Lemos Livros; 2014.

Araújo, C.A.Á. Mediação como conceito potencializador do diálogo entre a ciência da informação e os campos da arquivologia, biblioteconomia e museologia. In: Encontro Nacional de Pesquisa em Ciência da Informação 13., 2012, Rio de Janeiro. Anais eletrônicos [...]. Rio de Janeiro: Fiocruz, 2012. Disponível em: http://enancib.ibict.br/index.php/enancib/ xiiienancib/paper/viewFile/3714/2837. Acesso em: 13 set. 2018.

Araújo, C.A.Á.; Rocha, E.C.F. Panorama da produção do GT-3 da Ancib: autores, referências e temáticas (2005-2016). In: Encontro Nacional de Pesquisa em Ciência da Informação, 18., 2017, Marília, SP. Anais eletrônicos [...]. Marília: Unesp; 2017. Disponível em: http://enancib.marilia.unesp.br/index.php/ xviiienancib/ENANCIB/paper/viewFile/72/587. Acesso em: 20 set. 2018.

Bardin, L. Análise de conteúdo. Lisboa: Edições 70, 2005. p.36.

Bellotto, H.L. Difusão editorial, cultural e educativa em arquivos. In: Bellotto, H.L. Arquivos permanentes: tratamento documental. 4.ed. Rio de Janeiro: FGV, 2006. p.225-247.

Carvalho, J. Tópicos em Biblioteconomia e Ciência da Informação: epistemologia, política e educação. Rio de Janeiro: Agência Biblioo, 2016.

Duff, W.M. Mediação arquivística. In: Eastwood, T.; Macneil, H.H. (Org.). Correntes atuais do pensamento arquivístico. Belo Horizonte: UFMG, 2016. p.171-202.
Edgar, A.; Sedgwick, P. Teoria cultural de A a Z: conceitos-chave para entender o mundo contemporâneo. Belo Horizonte: Contexto, 2003. p.203.

Espírito Santo, S.M.; Murguia, E. Relações pendulares na mediação da informação: arquivo - biblioteca - museu. In: Encontro Nacional de Pesquisa em Ciência da Informação, 7., 2006, Marília. Anais eletrônicos [...]. Marília: Unesp, 2006. Disponível em: http://enancib.ibict.br/index.php/enancib/ viienancib/paper/viewFile/2475/1606. Acesso em: 13 set. 2018.

Farias, G.B.; Farias, M.G.G. Mediação na Ciência da Informação: uma análise bibliométrica na coleção Benancib. Revista Ibero-Americana de Ciência da Informação, v.10, n.2, p.332-349, 2017. Disponível em: http://periodicos. unb.br/index.php/ RICl/article/view/25215. Acesso em: 27 set. 2018.

Ferreira, L.E.; Almeida Júnior, O.F. A mediação da informação no âmbito da arquivística. Perspectivas em Ciência da Informação, v.18, n.1, p.158-167, 2013. Disponível em: http:// portaldeperiodicos.eci.ufmg.br/index.php/pci/article/ view/1270/1111. Acesso em: 20 set. 2018

Fialho, J.F.; Nunes, M.S.C; Carvalho, T. A mediação da informação nos grupos de pesquisa e no GT3 dos Enancib: espaços de comunicação científica em Ciência da Informação. Em Questão, v.23, n.2, p.252-276, 2017, Doi: http://dx.doi. org/10.19132/1808-5245232.252-276. Disponível em: https:// seer.ufrgs.br/index.php/EmQuestao/article/view/66952. Acesso em: 17 set. 2018.

Finazzi-Agrò, E. Mediações e medidas: o entre-lugar da interpretação. Outra Travessia, v.40, n.1, p.59-66, 2003. Disponível em: https://periodicos.ufsc.br/index.php/Outra/article/view/13 092/12171. Acesso em: 10 set. 2018.

Gama, F.A.; Ferneda, E. A mediação da informação nos arquivos permanentes: serviços de referência arquivística no ambiente digital. Informação \& Informação, v.15, n.2, p.148-169, 2010. Doi: http://dx.doi.org/10.5433/1981-8920. 2010v15n2p148. Disponível em: http://www.uel.br/revistas/ uel/index.php/informacao/article/view/7352. Acesso em: 22 set. 2018.

Gomes, H.F. A dimensão dialógica, estética, formativa e ética da mediação da informação. Informação \& Informação, v.19, n.2, p.46-59, 2014. Doi: http://dx.doi.org/10.5433/1981-8920. 2014v19n2p46. Disponível em: http://www.uel.br/revistas/uel/ index.php/informacao/article/view/19994. Acesso em: 27 set. 2018.

Grigoleto, M.C.; Aldabalde, T.V. Arquivologia e mediação: agenciamentos e visibilidades pelo saber/poder/fazer. In: Encontro Nacional de Pesquisa em Ciência da Informação, 17., 2016, Salvador. Anais eletrônicos [...]. Salvador: UFBA, 2016. Disponível em: http://repositorios.questoesemrede.uff. br/repositorios/handle/123456789/3231. Acesso em: 14 fev. 2018.

Lousada, M. A mediação da informação e a Arquivologia: aproximações teóricas. Pesquisa Brasileira em Ciência da Informação e Biblioteconomia, v.11, n.1, p.117-134, 2016. Disponível em: http://periodicos.ufpb.br/ojs2/index.php/pbcib/article/view/ 28 204/15247. Acesso em: 20 set. 2018. 
Lousada, M.; Almeida Júnior, O.F. A mediação da informação na teoria arquivística: aspectos epistemológicos. In: Encontro Nacional de Pesquisa em Ciência da Informação, 14., 2013. Anais eletrônicos [...]. Florianópolis: Ancib, 2013. Disponível em: http://enancib.ibict.br/index.php/enancib/xivenancib/ paper/view/4192/3315. Acesso em: 12 set. 2018.

Lousada, M.; Almeida Júnior, O.F. A mediação da informação na teoria arquivística. In: Encontro Nacional de Pesquisa em Ciência da Informação, 17., 2016, Salvador. Anais eletrônicos [...]. Salvador: UFBA, 2016. Disponível em: http:// repositorios.questoesemrede.uff.br/repositorios/handle/123 456789/3245. Acesso em: 14 set. 2018.

Malheiro, A.; Ribeiro, F. Mediações e mediadores no comportamento informacional: passado, presente e futuro. In: Malheiro, A.; Ribeiro, F. Paradigmas, serviços e mediações em Ciência da Informação. Recife: Néctar, 2011. p.144-194.

Morigi, V.J.; Veiga, A. Esfera pública informacional: os arquivos na construção da cidadania. Informação \& Sociedade: Estudos, v.17, n.2, p.31-39, 2007. Disponível em: http://periodicos.ufpb. br/index.php/ies/article/view/639/1444. Acesso em: 12 set. 2018.

Price, J.D.S. Litle science, big science. New York: Columbia University Press, 1963.

Rockembach, M. Difusão em arquivos: uma função arquivística, informacional e comunicacional. Informação Arquivística, v.4, n.1, p.98-118, 2015. Disponível em: http://www. aaerj.org.br/ojs/index.php/informacaoarquivistica/article/ view/95/55. Acesso em: 10 set. 2018.
Santa Anna, J.; Campos, S.O. Mediação da informação em arquivos: a necessidade da consolidação da prática do serviço de referência. Biblionline, v.12, n.2, p.68-83, 2016. Disponível em: http://www.periodicos.ufpb.br/ojs/index.php/biblio/ article/view/28257/15516. Acesso em: 11 set. 2018.

Santos, R.N.M.; Kobashi, N.Y. Bibliometria, cientometria, infometria: conceitos e aplicações. Tendências da Pesquisa Brasileira em Ciência da Informação, v.2, n.1, p.155-172, 2009. Disponível em: http://ojs.lat/tpbci/index.php/tpbci/article/ view/43. Acesso em: 28 ago. 2018.

Santos Neto, J.A.; Bortolin, S. Mediação da informação: afinando o foco na Arquivologia. In: Moura, M.A.; Silveira, F.J.N. (Org.). Encontro da Associação de Educação e Pesquisa em Ciência da Informação da Íbero-América e Caribe, $10 .$, Belo Horizonte. Anais [...] Belo Horizonte: ECI/UFMG, 2017. Disponível em: http://edicic2016.eci.ufmg.br/anais/\#artigos. Acesso em: 10 set. 2018.

Silva, M.R.; Hayashi, C.R.M.; Hayashi, M.C.P.I. Análise bibliométrica e cientométrica: desafios para especialistas que atuam no campo. Revista de Ciência da Informação e Documentação, v.2, n.1, p.110-129, 2011. Doi: http://dx.doi.org/10.11606/issn. 2178-2075.v2i1p110-129. Disponível em: http://www.revistas. usp.br/incid/article/view/42337. Acesso em: 28 ago. 2018.

Teixeira Coelho, J. Dicionário crítico de política cultural: cultura e imaginário. São Paulo: Iluminuras, 1997. p.248.

Urbizagástegui Alvarado, R. Elitismo na literatura sobre a produtividade dos autores. Ciência da Informação, v.38, n.2, p.69-79, 2009. Disponível em: http://revista.ibict.br/ciinf/ article/view/1246/1424. Acesso em: 19 set. 2018. 